\title{
Psychological Well Being ditinjau dari Perilaku Prososial pada Siswa
}

\author{
Angellina, Anissa Mifthahurahma Sihombing, Emelia Debora Pinem, Sri Hartini \\ Universitas Prima Indonesia \\ Email: angellinatan@hotmail.com, anisa.ich4@gmail.com, emeliadebora123@gmail.com
}

\begin{abstract}
Adolescent development period is a critical period where there is a transition of development from childhood to adulthood about their mental function, physical, and their psychological. For the sake to support teenager can grow in accordance with their mental age, teenagers are expected to have a high psychological well-being. Give them a chance to get involve in an useful activity so that can increase their willingness to engage in prosocial behavior in the future. Based on the above background this study aims to determine whether there is a relationship between prosocial behavior with psychological well being on X class students at SMA Negeri 13 Medan. The sample on this study amounted to 142 students. The following instruments were used are Physicological Well Being Scale based on Ryff theory, and Prosocial Behaviour Scale which constructed based on Schroeder and Graziano theory. The results of data analysis using Pearson Product Moment showed $r$ $=0,371$ with $p=0.000(p<0.05)$. It means there is a positive and significant between prosocial behaviour with psychological well being on X class students at SMA Negeri 13 Medan, the higher prosocial behaviour are, the higher level of psychological well being on X class students on SMA Negeri 13 Medan.
\end{abstract}

Keywords : psychological well being, prosocial behaviour, student

\begin{abstract}
Abstrak
Perlaihan perkembangan yang terjadi dari masa kanak - kanak menuju ke masa dewasa merupakan masa yang kritis yang terjadi pada masa perkembangan remaja mulai dari fungsi mentalnya, fungsi fisik, dan juga psikologisnya. Seorang remaja diharapkan untuk memiliki psychological well being yang tinggi agar dapat mendukung masa perkembangannya yang sesuai dengan usia mentalnya. Memberi peluang untuk terlibat dalam kegiatan yang bermanfaat dapat meningkatkan kesediaan mereka untuk terlibat perilaku prososial di masa yang akan datang. Berdasarkan hal tersebut di atas penelitian ini bertujuan untuk mengetahui apakah ada hubungan antara perilaku prososial dengan psychological well being pada siswa kelas X di SMA Negeri 13 Medan. Sampel dalam penelitian ini berjumlah 142 orang. Metode pengumpulan data yang digunakan adalah dengan menggunakan Skala Psychological Well Being yang disusun peneliti berdasarkan teori dari Ryff (dalam Papalia, dkk., 2005) dan Skala Prososial yang disusun peneliti berdasarkan teori dari Schoroeder dan Graziano (2015). Analisis data menggunakan korelasi Pearson Product Moment menunjukkan $r=0.371$ dengan $p=0.000(p<0.05)$. Hal ini menunjukkan bahwa terdapat hubungan yang positif dan signifikan antara perilaku prososial dengan psychological well being pada siswa kelas X di SMA Negeri 13 Medan, semakin tinggi perilaku prososial, maka psychological well being pada siswa kelas X di SMA Negeri 13 Medan semakin tinggi.
\end{abstract}

Kata kunci : kesehahteraan psikologis, perilaku prososial, siswa

\section{Pendahuluan}

Sama halnya dengan seseorang anak murid yang memerlukan teman, guru, kepala sekolah, dan orang - orang lainnya yang ada di sekolah demi kelancaran dalam berkegiatan di sekolah, manusia pada umumnya juga tidak dapat lepas dari interaksi sosial dengan orang lain dalam melakukan berbagai kegiatan maupun melakukan pekerjaan pada suatu tempat. Aspek biologi, kognitif, dan sosioemosional merupakan hal yang menandai perubahan berbagai aspek bahwa masa peralihan masa remaja merupakan perjalanan antara anank - anak ke dewasa. (Santrock, 2003)

fase remaja ditandai dengan keadaan yang tidak menentu (labil), baik itu dalam bentuk afeksi atau perasaan maupun perilakunya. Dengan perasaan yang tidak terkontrol ini emosi para remaja sering dikaitkan dengan banyaknya kegiatan yang dilakukan baik itu di dalam rumah maupun di luar rumah (sekolah). Dari segi perilaku, remaja cenderung mudah dipengaruhi oleh pendapat ataupun ajakan teman-temannya.

Diterima Redaksi: 04-04-2020 | Selesai Revisi: 07-05-2020 | Diterbitkan Online: 01-06-2020 
Hal yang dapat menjadikan remaja menjadi mampu untuk melakukan penyesuaian diri dengan lingkungan sosial dan juga dengan dirinya sendiri adalah pola interaksi sosial. Untuk persiapan seorang remaja dalam menghadapi masa dewasanya yang lebih mandiri, mereka diharapkan untuk dapat melakukan hal-hal positif dalam mengisi kehidupan masa remajanya. Agar para remaja dapat menjadi penerus generasi bangsa yang kuat dan bermanfaat untuk orang banyak, maka mereka diharapkan untuk mempunyai tingkat psychological well being yang tinggi agar dapat mendukung perkembangan mereka sesuai dengan usia mentalnya. Psychological well being merupakan hal penting yang perlu diperhatikan pada masa remaja. Fenomena yang terjadi kepada beberapa pelajar memiliki semangat belajar yang berbeda, ada yang memiliki semangat yang tinggi adapula semangat belajar yang rendah walaupun ketika jam sekolah mereka memilih untuk bersenang-senang sehingga muncul masalah-masalah yang terjadi pada kasus dimana terdapat beberapa pelajar yang kedapatan sedang berada di luar sekolah saat jam pelajaran di sekolah sedang berlangsung yang diamankan oleh Petugas Polsek Kawangkoan.Saat dijaring oleh petugas pelajar tersebut tengah asyik nongkrong di rumah makan dan rumah kopi yang ada di Kelurahan Talikuran, Kecamatan Kawangkoan Utara. Terdapat 17 pelajar yang dijaring, dan mereka berasal dari dua sekolah berbeda. Kapolsek Kawangkoan Iptu Nofri Umar mengatakan, tindakan yang diambil berdasarkan laporan warga yang resah melihat tingkah para pelajar ini yang sering kumpul dan merokok di saat jam pelajaran sekolah sehingga Waka Polsek Kawangkoan Ipda Woltein Carlos memerintah personil untuk mendatangi TKP dan ternyata benar bahwa di rumah makan maupun rumah kopi yang ada di Kelurahan Talikuran didapati para pelajar yang masih menggunakan seragam sekolah namun tidak masuk sekolah dan ditempat nongkrong mereka pula ditemukan bekas puntung rokok. (www.tribunmanado.co.id)

Berdasarkan hasil observasi dan wawancara yang dilakukan peneliti pada siswa SMAN 13 Medan terdapat beberapa siswa yang nakal. Para pelajar lebih memilih bermain gadget mereka daripada bermusyawarah dengan guru dan mengabaikan guru ketika jam sekolah berlangsung sehingga prestasi belajar mereka juga rendah. Terlihat pula beberapa bangku kosong di kelas, menurut sang guru, beliau mengatakan bahwa siswa tersebut sebagian bolos di jam pelajaran walaupun sudah dinasihati, mereka juga sering melawan gurunya. Banyak pula siswa yang berpakaian kurang rapi, ada yang tidak memakai dasi, baju dikeluarkan, sepatu berwarna dan mereka mengatakan itu adalah tren masa kini dan berpakaian rapi itu kuno.

Kemajuan teknologi yang pesat membuat mereka kian bebas tanpa difilter terlebih dahulu. Terlambat juga merupakan hal yang sudah umum, ketika jam pelajaran sudah dimulai tampak beberapa siswa yang masih baru sampai dalam ruang kelas tidak jauh berbeda ketika jam istirahat sudah selesai pun tampak beberapa pelajar yang masih kumpul di kantin sekolah padahal guru sudah memasuki ruangan kelas. Ketika guru memasuki kelas dengan membawa tugas para siswa yang banyak dan berat kurang ada inisiatif pula para pelajar yang membantu guru yang terlihat kesusahan dan tampak kelihatan kurang kepedulian mereka.

Berdasarkan pada kasus dan hasil survei yang diuraikan di atas pada kalangan remaja khususnya seorang siswa, dapat dilihat bahwa, para pelajar tersebut kurang memiliki kepercayaan diri dan emosi yang masih kurang stabil. Pengembangan karakter dan kepribadian yang baik dimulai dari dalam rumah dimana pola asuh yang ditanamkan oleh orang tua pada anak akan membuat anak tumbuh dan berkembang menjadi pribadi yang baik. Hal ini juga dibarengi dengan ajaran yang diterima murid dari gurunya disekolah. Dengan karakter pribadi yang baik tadi akan menumbuhkan sikap saling tolong menolong pada remaja agar tercapainya kesejahteraan psikologis.

Salah satu faktor yang mempengaruhi psychological well being menurut Setyawati (2015) adalah perilaku prososial. Hasil penelitian yang dilakukan membuktikan bahwa psychological well being dipengaruhi oleh perilaku prososial yang menunjukkan bahwa adanya hubungan 
positif dan signifikan bahwa semakin tinggi perilaku prososial yang dimiliki maka psychological well being remaja juga akan tinggi, begitu pula sebaliknya. Individu yang memiliki tingkat kesejahteraan yang tinggi memiliki tujuan hidup yang lebih baik dari sebelumnya dan juga memiliki karakter dan pribadi yang baik dengan orang lain.

Agar siswa dapat memiliki sikap perilaku prososial maka mereka diharapkan untuk dapat menerapkan semua aspek dari kesejahteraan psikologis tersebut ke dalam hidup mereka setiap harinya guna tercapainya psychological well being yang baik dan juga dapat terciptanya sikap prososial yang diinginkan.

Seorang penolong yang dapat membuat seorang penerima pertolongan menjadi lebih baik hidupnya baik dari segi psikologisnya maupun materil disebut merupakan salah satu tujuan dalam perilaku prososial yang di jelaskan oleh William (dalam Dayakisni dan Hudaniah, 2003).

Pada masa-masa remaja perilaku prososial lebih banyak ditemukan (Eisenberg dalam Santrock, 2007). Berbagai macam tantangan juga ditemukan dalam rentan usia remaja, dan ini merupakan salah satu teori dari Hall (dalam Santrock, 2007)

Berdasarkan masalah-masalah yang diuraikan serta latar belakang di atas menunjukkan adanya rasa kepedulian yang rendah, kurangnya minat belajar, kurangnya rasa sosial yang membuat kesejahteraan psikologis kurang dalam kehidupan dilingkungan sekitar. Hal tersebut diatas mendorong peneliti untuk mengadakan penelitian dengan judul Psychological WellBeing ditinjau dari Perilaku Prososial.

Penelitian ini dilakukan untuk mengetahui hubungan antara perilaku prososial dengan psychological well being pada siswa. Secara teoritis hasil penelitian ini bertujuan dapat digunakan sebagai sumbangan dalam ilmu psikologi pada umumnya dan dalam bidang psikologi sosial dan bidang bimbingan dan konseling pada khususnya.

\section{MetodePenelitian}

Penelitian ini menggunakan jenis penelitian kuantitatif dengan psychological well being sebagai variable terikat, dan perilaku prososial sebagai variable bebas. Teknik pengambilan sampel yang digunakan yaitu dengan menggunakan teknik sampling jenuh dimana 100 persen populasi digunakan sebagai sampel yang berjumlah 142 responden, populasi tersebut adalah siswa - siswi SMA kelas X di SMA Negeri 13 Medan. Penelitian ini menggunakan metode dua skala yaitu skala Psychological Well Being yang dibuat berlandaskan aspek Ryff (dalam Papalia dkk., 2005), dan juga menggunakan skala Perilaku Prososial yang dibuat berlandaskan aspek Schoroeder dan Graziano (2015), yang disusun dengan skala likert. Skala - skala tersebut dituangkan ke dalam beberapa pernyataan yang terdiri dari pernyataanpernyataan favourable dan juga unfavorable, diisi dengan empat jawaban alternatif.

Jawaban-jawaban yang mendukung atau favourable menurut Sugiyono (2010) diberi nilai yaitu untuk item-item favorable akan diberi nilai 1 pada pilihan jawaban (STS), nilai 2 pada pilhan jawaban (STS), nilai 3 pada pilihan jawaban (S), dan nilai 4 pada pilihan jawaban (SS), kemudian untuk item-item unfavorable akan diberikan nilai 1 pada pilihan jawaban (SS), nilai 2 pada pilihan jawaban (S), nilai 3 pada pilihan jawaban (TS), dan nilai 4 pada pilihan jawaban (STS). Menurut Sugiyono (2010) pembagian skala merupakan cara yang digunakan untuk melangsungkan teknik pengumpulan data di dalam penelitian.

Validitas isi merupakan validitas yang digunakan dalam alat ukur perilaku prososial dan psychological well-being adalah validitas isi. Ketetapan logika tentang kecocokan aitem dengan tujuan ukur skala tidak mungkin hanya berdasar kepada penilaian penulis melainkan perlu persetujuan dari beberapa penilai yang handal tentu tidak diperlukan kesepakatan penuh dari semua penilai yang menyatakan bahwa aitem adalah relevan dengan tujuan ukur skala. (Azwar 2012) 
Selanjutnya, uji realibilitas, Sugiyono (2016) menjelaskan bahwa akan tetap sama data yang didapat jika instrumennya dipakai berulangkali. Instrumen yang dimaksud adalah instrumen reliable. Menurut Azwar (2012) jika suatu penelitian membentuk hasil data yang sama maka data tersebut tetap dinyatakan reliable. Hal ini dilihat dari sudut pandang kuantitatif.

Azwar (2012) mengungkapkan bahwa koefisien yang baik adalah dengan merujuk pada angka 0 - 1,00 dimana semakin tinggi koefisien ditunjukkan dengan angka 1,00 dan sebaliknya semakin rendah koefisien menunjukkan dibawah angka 0 . Metode yang dipergunakan yaitu metode Conbrach Alpha. Jika nilai Cronbach Alpha > 0,60 maka kuesioner tersebut terbilang reliable.Untuk mengetahui suatu data apakah distribusi normal atau tidak normal maka dilakukanlah uji normalitas dengan menggunakan Kolmogrov-Smirnov dengan syarat bila $\mathrm{p}$ lebih besar dari 0,05 maka data yang dihasilkan dapat disebut distribusi normal begitu juga sebaliknya bila $\mathrm{p}$ lebih kecil dari 0,05 maka datanya disebut tidak distribusi normal.

Kemudian dalam penelitian ini juga akan dilakukan uji linearitas untuk melihat kedua variabel tersebut memiliki hubungan yang linear. Uji linearitas dilakukan untuk mengetahui bahwa data kedua variabel yang dianalisis dalam metode statistika analisis hubungan menunjukkan adanya relasi antara linier atau tidak. Ditandai dengan $\mathrm{p}<0,05$ maka bisa diartikan variabel perilaku prososial dengan variabel psychological well being dikatakan linear, begitu juga sebaliknya.

\section{Hasil dan Pembahasan}

Sebelum dilakukan penelitian dilakukan uji coba alat ukur pada siswa siswi kelas X pada 28 November 2019 sebanyak 70 siswa. Uji validitas dalam try out penelitian ini menggunakan metode corrected item total correlation, yang mana aitem valid dapat dilihat pada tabel corrected item-total correlation dengan nilai $\mathrm{r}$ bergerak dari 0.313-0.657 pada skala psychological well being. Hasil uji coba alat ukur untuk mengungkap psychological well being menunjukkan bahwa 30 dari 48 aitem dinyatakan sahih. Sedangkan untuk skala perilaku prososial nilai $r$ bergerak dari 0.309-0.659. Hasil uji coba alat ukur untuk mengungkap perilaku prososial menunjukkan bahwa 31 dari 48 aitem dinyatakan sahih.

Tahap selanjutnya adalah melakukan pengujian reliabilitas dengan menggunakan teknik Alpha Cronbach yang diolah melalui data SPSS versi 18 for windows. Dari hasil data analisis yang dilakukan maka diperoleh hasil koefisien reliabilitas Alpha Coonbrach sebesar 0,887.

Selanjutnya dilakukan penelitian pada tanggal 11 Desember 2019 yang ditujukan kepada 142 siswa-siswi di SMA Negeri 13 Medan. Pengambilan data dimulai dengan membagikan skala penelitian berupa skala psychological well-being yang valid sebanyak 30 aitem dan skala perilaku prososial yang valid sebanyak 31 aitem. Batas atas dan bawahnya dari 30x1 hingga $30 \times 4$, berkisar antara 30 hingga 120 untuk mean hipotetiknya adalah $(30+120): 2=75$. Standar perhitungan dalam pelitian ini $(120-30): 6=15$. Berdasarkan skala psychological well-being yang berisi maka subjek maka mean empirik sebesar 91.13 dengan standard deviasi 5.042. Perbandingan data empirik dan hipotetik dapat dilihat pada tabel 1.

Tabel 1. Perbandingan Data Empirik dan Hipotetk Psychological Well Being

\begin{tabular}{ccccccccc}
\hline Variabel & \multicolumn{3}{c}{ Empirik } & \multirow{2}{*}{ SD } & \multicolumn{3}{c}{ Hipotetik } & \multirow{2}{*}{ SD } \\
\cline { 1 - 2 } $\begin{array}{l}\text { Psychological } \\
\text { Well Being }\end{array}$ & Min & Maks & Mean & & Min & Maks & Mean & \\
\hline
\end{tabular}

Jumlah dari proses perhitungan skala psychological well-being didapatkan mean empirik > mean hipotetik yaitu $91.13>75$ jadi dapat dikatakan psychological well-being populasi subjek lebih tinggi dibandingkan populasi pada umumnya. Dalam kajian ini didapatkan Standart deviasi hipotetik $\sigma=(120-30): 6=15$ sedangkan mean hipotetiknya $\mu=(30+$ 120) $: 2=75$.bedasarkan penjumlahan diatas bisa lanjutkan dengan proses memakai rumus 
yang telah djabarkan sebelumnya, diperoleh $\mathrm{x}<(75-15)=\mathrm{x}<60,(75-15)<\mathrm{x} \leq(75+15)=60$ $<\mathrm{x} \leq 90$ dan $\mathrm{x} \geq(75+15)=\mathrm{x} \geq 90$. Untuk pembagian data psychological well-being dijabarkan pada Tabel 2 dibawah ini :

Tabel 2. Kategorisasi Data Psychological Well Being

\begin{tabular}{ccccc}
\hline Variabel & Rentang Nilai & Kategori & Jumlah $(\mathrm{n})$ & Presentase \\
\hline \multirow{2}{*}{$\begin{array}{c}\text { Psychological Well } \\
\text { Being }\end{array}$} & $\mathrm{x}<60$ & Rendah & 0 & $0 \%$ \\
\cline { 2 - 5 } & $60<\mathrm{x} \leq 90$ & Sedang & 49 & $34.50 \%$ \\
\cline { 2 - 5 } & $\mathrm{x} \geq 90$ & Tinggi & 93 & $65.50 \%$ \\
\hline & Total & & 142 & $100 \%$ \\
\hline
\end{tabular}

Dari pembagian di tabel 2 bisa perhatikan maka dapat dilihat bahwa psychological well-being di kategori rendah dengan 0\%subjek, sedangkan psychological well-being sedang $34.50 \%$ atau 49 subjek, selanjutnya psychological well-being tinggi sebanyak $65.50 \%$ atau 93 subjek. Jadi bisa diartikan dari sekian subjek dari kajian ini memiliki rata - rata berada pada kategori psychological well-being tinggi.

Skala perilaku prososial terdiri dari 31 aitem yang memiliki 4 pembahagian dengan nilai 1 sampai 4 batas atas dan bawahnya berkisar $31 \times 1$ dan $31 \times 4$, dengan nilai 31 menuju 124 yang mana mean hipotetiknya $(31+124): 2=77.5$. Standard deviasi hipotetik dalam kajian ini adalah (124-31) : $6=15.5$.

Berdasarkan skala perilaku prososial, didapatkan mean empirik senilai 94.89 dengan standard deviasi 4.700. Perbandingan data empirik dan hipotetik dapat dilihat pada Tabel 3.

Tabel 3. Perbandingan Data Empirik dan Hipotetk Perilaku Prososial

\begin{tabular}{|c|c|c|c|c|c|c|c|c|}
\hline \multirow{2}{*}{$\frac{\text { Variabel }}{\text { Perilaku }}$} & \multicolumn{3}{|c|}{ Empirik } & \multirow{2}{*}{ SD } & \multicolumn{3}{|c|}{ Hipotetik } & \multirow{2}{*}{$\mathrm{SD}$} \\
\hline & Min & Maks & Mean & & Min & Maks & Mean & \\
\hline Prososial & 80 & 106 & 94.89 & 4.700 & 31 & 124 & 77.5 & 15.5 \\
\hline
\end{tabular}

Proses perilaku prososial didapati $94.89>77.5$ jadi bisa dikatakan bahwa perilakuprososial pada subjek penelitian lebih tinggi daripada populasi pada umumnya. Standart penyimpangan hipotetik dikajian ini $\sigma=(124-31): 6=15.5$ sedangkan mean hipotetiknya $\mu=(31+124)$ : $2=77.5$. berdasarkan penjumlahan diatas bisa dilanjutkan penjumlahan menggunakan rumus yang telah diuraikan di atas, diperoleh $\mathrm{x}<(77.5-15.5)=\mathrm{x}<62,(77.5-15.5)<\mathrm{x} \leq(77.5+15.5)$ $=62<\mathrm{x} \leq 93$ dan $\mathrm{x} \geq(77.5+15.5)=\mathrm{x} \geq 93$. Untuk pembagian data perilaku prososial di jabarkan pada table di bawah ini :

Tabel 4. Kategorisasi Data Perilaku Prososial

\begin{tabular}{ccccc}
\hline Variabel & Rentang Nilai & Kategori & Jumlah (n) & Presentase \\
\hline \multirow{3}{*}{ Perilaku Prososial } & $\mathrm{x}<62$ & Rendah & 0 & $0 \%$ \\
\cline { 2 - 5 } & $62<\mathrm{x} \leq 93$ & Sedang & 38 & $26.77 \%$ \\
\cline { 2 - 5 } & $\mathrm{x} \geq 93$ & Tinggi & 104 & $73.23 \%$ \\
\hline & Total & & 142 & $100 \%$ \\
\hline
\end{tabular}

Dari pembagian pada table diatas bisa Tarik kesimpulan 0\% subjek berperilaku rendah, 2,77\% untuk perilaku sedang dan $73.23 \%$ berperilaku tinggi. Berdasarkan penjelasan di atas maka dapat disimpulkan bahwa rata-rata subjek penelitian memiliki perilaku prososial tinggi.

Menurut Priyatno (2011), adapun kriteria yang digunakan adalah $\mathrm{P}>0.05$ maka data berdistribusi normal dan sebaliknya jika $\mathrm{P}<0.05$ maka data tidak berdistribusi normal. Uji 
normalitas yang dilakukan terhadap variabel psychological well-being diperoleh koefisien $\mathrm{KS}-\mathrm{Z}=0.965$ dengan Sig sebesar 0.310 untuk uji 2 (dua) arah dan Sig sebesar 0.155 untuk uji 1 (satu) arah ( $\mathrm{p}>0.05)$, artinya skor psychological well-being mengikuti distribusi normal. Uji normalitas pada variabel perilaku prososial diperoleh koefisien KS-Z $=1.038$ dengan Sig sebesar 0.232 untuk uji 2 (dua) arah dan Sig sebesar 0.116 untuk uji 1 (satu) arah (p >0.05), yang berarti bahwa data pada variabel perilaku prososial memiliki sebaran atau berdistribusi normal. Hasil uji normalitas dapat dilihat melalui tabel 5.

Tabel 5. Hasil Uji Normalitas

\begin{tabular}{cccccc}
\hline Variabel & SD & KS-Z & Sig. & P & Keterangan \\
\hline $\begin{array}{c}\text { Psychological } \\
\text { Well Being }\end{array}$ & 5.042 & 0.965 & 0.310 & $\mathrm{p}>0.05$ & Sebaran normal \\
\hline $\begin{array}{c}\text { Perilaku } \\
\text { Prososial }\end{array}$ & 4.700 & 1.038 & 0.232 & $\mathrm{p}>0.05$ & Sebaran normal \\
\hline
\end{tabular}

Setelah dilakukan pengujian normalitas maka dilakukan uji linearitas digunakan untuk mengetahui apakah distribusi data penelitian yaitu variabel psychological well-being dan perilaku prososial memiliki hubungan linier Uji F (Anova). Variabel psychological well-being dan perilaku prososial dikatakan memiliki hubungan linier jika $\mathrm{p}<0.05$. Hasil uji linieritas dapat dilihat pada tabel 6.

Tabel 6. Hasil Uji Linearitas Hubungan

\begin{tabular}{cccccc}
\hline Variabel & $\mathrm{F}$ & Sig & $\mathrm{P}$ & Keterangan \\
\hline Psychological Well Being & Perilaku Prososial & 22.272 & 0.000 & $\mathrm{P}<0.05$ & Linear \\
\hline
\end{tabular}

Berdasarkan tabel 6 dapat diambil kesimpulan bahwa variabel psychological well-being dan perilaku prososial memiliki hubungan linear. Hal ini terlihat dari nilai sig yang diperoleh yaitu 0.000 maka $\mathrm{p}<0.05$, dapat disimpulkan bahwa kedua variabel memiliki hubungan linear dan telah memenuhi syarat untuk dilakukan analisa korelasi Product Moment.

Setelah uji asumsi diterima, selanjutnya dilakukan uji hipotesis. Hipotesis dalam penelitian ini menunjukkan hubungan positif dan signifikan antara perilaku prososial dan psychological well-being. Berdasarkan tujuan penelitian maka dilakukan uji Pearson Correlation. Hasil uji statistik dapat dilihat pada tabel 7.

Tabel 7. Korelasi Antara Psychological Well Being dengan Perilaku Prososial

\begin{tabular}{|c|c|c|c|}
\hline Variabe & & Pearson Correlation & Signifikansi (p) \\
\hline Psychological Well Being & Perilaku Prososial & 0.371 & 0.000 \\
\hline
\end{tabular}

Berdasarkan hasil analisis korelasi antara perilaku prososial dengan psychological well-being, diperoleh koefisien korelasi product moment sebesar $\mathrm{r}=0.371$ dengan sig sebesar $0.000(\mathrm{p}<$ 0.05). Hal ini menunjukkan bahwa adanya korelasi positif antara perilaku prososial dengan psychological well-being. Dengan demikian, dapat disimpulkan bahwa semakin tinggi perilaku prososial, maka psychological well-being semakin tinggi dan sebaliknya semakin rendah perilaku prososial, maka psychological well-being semakin rendah. Berdasarkam hasil perhitungan tersebut, maka hipotesis yang diajukan dalam penelitian ini menunjukkan ada hubungan positif antara perilaku prososial dengan psyhcological well being.

Adapun hasil penelitian ini juga sejalan dengan penelitian yang dilakukan Megawati dan Herdiyanto (2016). Megawati dan Herdiyanto (2016), mengemukakan bahwa perilaku prososial adalah salah satu faktor yang mempengaruhi psychological well- being. 


\section{Kesimpulan}

Menurut hasil dari proses perhitungan yang di lakukan dalam kajian ini maka bisa diartikan terdapat relasi yang tegas dan signifikan dari perilaku prososial dengan psychological wellbeing yang memiliki nilai koefisien korelasi product moment $=0.371 \mathrm{dan} \mathrm{p}=0.000(\mathrm{p}<$ 0.005), artinya semakin tinggi perilaku prososial yang dimiliki oleh siswa-siswi kelas $\mathrm{X}$ di SMAN 13 Medan, maka semakin tinggi psychological well-being, dan sebaliknya jika semakin rendah perilaku prososial, maka semakin rendah psychological well-being pada siswa-siswi kelas X di SMAN 13 Medan. Mean dari psychological well-being pada subjek penelitian siswa-siswi kelas X di SMAN 13 dari data umum memperlihatkan nilai subjek pada psychological well-being menunjukan nilai maksimum dibandingkan populasi pada umumnya. Hal ini dapat dilihat dari nilai mean empirik 91.31 lebih tinggi dari mean hipotetik yaitu 75. Mean dari perilaku prososial pada subjek penelitian siswa-siswi kelas X di SMAN 13 Medan secara keseluruhan menunjukkan bahwa perilaku prososial subjek penelitian lebih tinggi dari pada populasi pada umumnya. Hal ini dapat dilihat dari nilai mean empirik sebesar 94.89 lebih tinggi dari mean hipotetik yaitu 77.5. Hasil penelitian ini menunjukkan bahwa sumbangan yang diberikan variabel perilaku prososial terhadap variabel psychological wellbeing adalah sebesar 13.7 persen dan selebihnya 86.3 persen dipengaruhi oleh faktor lain, seperti Loneliness, religiusitas dan stres.

\section{Daftar Rujukan}

Ali, M \& Asrori, M. (2004). Psikologi Remaja Perkembangan Peserta Didik. Jakarta : PT Bumi Aksara

Anggraeni, R.D. (2011). Hubungan antara Religiusitas dan Stres dengan Psychological Well Being pada Remaja Pondok Pesantren. Jurnal Psikologi Teori \& Terapan, Volume 2 No. 1. Diakses 28 Desember 2018, dari EJournal Universitas Negeri Surabaya.

Arikunto, S. (2009). Manajemen Penelitian. Jakarta : Penerbit Rineka Cipta

Asih, G.Y \& Pratiwi, M.M.S. (2010). Perilaku Prososial ditinjau dari Empati dan Kematangan Emosi. Jurnal Psikologi Universitas Muria Kudus, Volume I No. 1. Diakses pada 22 Desember 2018, dari E-Journal Univeritas Muria Kudus.

Azwar, S. (2012). Penyusunan Skala Psikologi. Yogyakarta : Pustaka Pelajar

Baron, R.A. (2004). Psikologi Sosial Jilid 1. Jakarta : Erlangga

Bhagchandani, R.K. (2017). Effect of Lonliness on the Psychological Well-Being of College Students. International Journal of Social Science and Humanity Volume 7 No. 1. Diakses dari http://ijssh.org

Biddle, S.J.H. Physical Activity and Psychological Well-Being. USA : Routledge. Diakses pada 17 Januari 2019, dari https://books.google.co.id/books

Bornstein, M.H. Dkk. (2003). Well-Being. Positive Development Across the Life Course. London : Lawrence Erlbaum Associates,Publisher. Diakses pada 21 Desember 2018, dari https://books.google.co.id/books

Brown, R \& Gaertner, S. (2003). Blackwell Handbook of Social Psychology : Intergroup Process. Berlin : Blackwell Publishing Company. Diakses dari https://books.google.co.id/books

Busro, M. (2018). Teori - Teori Manajemen Sumber Daya Manusia edisi ke 1. Jakarta : Prenadamedia Group

Dayakisni, Tri \& Hdaniah. (2003). Psikologi Sosial. Malang : UMM Press

Eisenberg, N \& Mussen, P.H. (2003). The Roots of Prosocial Behaviour in Children. United Kongdom : Cambridge University Press

Hamdi, A. S \& Bahruddin, E. (2014). Metode Penelitian Kuantitatif Aplikasi dalam Pendidikan. Yogyakarta : CV Budi Utama

Haybron, D.M. (2008). The Prusuit of Unhappiness. The Elusive Psychology of Well-Being. United States : Oxford University Press.

Henriques, J. Dkk. (2005). Changing the Subject. Psychology, Social Regulation and Subjectivity. London dan New York : Routledge.

Husada, A.K. (2013). Pengaruh Pola Asuh Demokratis dan Kecerdasan Emosi dengan Perilaku Prososial pada Remaja. Persona, Jurnal Psikologi Indonesia Volume 2 No. 3 Hal 266-277.

Lupitasari, N \& Fauziah, N. (2017). Hubungan antara Harga Diri dengan Kecenderungan Perilaku Prososial pada Remaja Panti Asuhan di Semarang. Jurnal Empati Volume 7 No. 3 Halaman 318-322. Diakses pada 22 Desember 2018, dari https://ejournal3.undip.ac.id/index.php/empati/article/view/19761 
Megawati, E \& Herdiyanto, Y.K. (2016). Hubungan antara Perilaku dengan Psychological Well-Being pada Remaja. Jurnal Psikologi Udayana Volume 3 No. 1 ISSN: 2354 5607. Diakses pada 19 Desember 2018, dari https://ojs.unud.ac.id/index.php/psikologi/article/view/25228

Millon, T \& Lerner, M.J. (2003). Handbook of Psychology. Volume 5. Personality and Social Psychology. New Jersey : John Wiley \& Sons.

Petranto, I. (2005). It takes Only One to Stop the Tango. Tanggerang : PT Kawan Pustaka

Prisgunanto, I. (2004). Praktik Ilmu Komunikasi dalam Kehidupan Sehari - hari. Jakarta : Teraju

Ramdhani, N. Dkk. (2018). Psikologi untuk Indonesia Tangguh dan Bahagia. Yogyakarta : Gadjah Mada University Press

Santosa, P.B., \& Ashari. (2005). Analisis Statistik dengan Microsoft Ecel \& SPSS. Yogyakarta : Penerbit Andi

Santrock, J. W. (2003). Adolescence. Edisi keenam. Jakarta : Erlangga

Schroeder, D.A \& Graziano, W.G. (2015). The Oxford Handbook of Prosocial Behaviour. New York : Oxford University Press

Setyawati, A. (2015). Hubungan antara Perilaku Prososial dengan Kesejahteraan Psikologis (Psychological Well-Being) pada Siswa Kelas XI di SMK Muhammadiyah 2 Yogyakarta. Jurnal Bimbingan dan Konseling $\begin{array}{lllllllll}\text { Edisi } & 12 & \text { Tahun } & \text { ke } & 4 & \text { Diakses }\end{array}$ http://journal.student.uny.ac.id/ojs/index.php/fipbk/article/view/305

Sholiha, R., Bintari, D.R., \& Nurwianti, F. (2015). Hubungan Trait dan Psychological Well-Being pada Masyarakat Kota Jakarta. Seminar Psikologi \& Kemanusiaan ISBN: 978-979-796-324-8.

Sugiyono, (2010). Metode Penelitian Kuantitatif, Kualitatif, dan R\&G. Bandung : Alfa Beta

Susanto, A. (2011). Perkembangan Anak Usia Dini edisi ke 1. Jakarta : Prenadamedia Group

Susanto, A. (2015). Bimbingan dan Konseling di Taman Kanak - Kanak edisi ke 1. Jakarta : Prenadamedia Group

Susanto, A. (2018). Bimbingan dan Konseling di Sekolah (Konsep, Teori, dan Aplikasinya) edisi ke 1. Jakarta : Prenadamedia Group

Swarjana, I. K. (2012). Metode Penelitian Kesehatan. Jakarta : CV Andi Offset

Tribunews, 2019. Siswa Kedapatan Bolos Sekolah. Begini tindakan polsek Langowan. [Online] (Updated 13 Mar 2019) Tersedia di : https://manado.tribunnews.com/

Tridiana, R. (2015). Pengaruh Kematangan Emosi terhadap Perilaku Prososial Remaja Pengguna Gadget di SMPN 2 Yogyakarta. E-Journal Bimbingan dan Konseling Edisi 10 Tahun ke 4

Tersedia di : https://eprints.uny.ac.id/26171/ . [Accessed 27 November 2018]

Umar, H. (2003). Metode Riset Bisnis. Jakarta : Gramedia

Wicaksono, M.L.H \& Susilawati, L.K.P.A. (2016). Hubungan Rasa Syukur dan Perilaku Prososial terhadap Psychological Well-Being pada Remaja Akhir Anggota Islamic Medical Activists Fakultas Kedokteran Universitas Udayana. Jurnal Psikologi Udayana Volume 3 No. 4 ISSN: 2354 5607. Diakses tanggal 20 Desember 2018 dari https://ojs.unud.ac.id/index.php/psikologi/article/view/25234

Yantiek, E. (2014). Kecerdasan Emosi, Kecerdasan Spiritual dan Perilaku Prososial Remaja. Jurnal Psikologi Indonesia Volume 3 No. 01 Hal 22-31. Diakses pada tanggal 22 Desember 2018 dari http://jurnal.untagsby.ac.id/index.php/persona/article/view/366 